\title{
American Board of Family Medicine Heart Failure Self-Assessment Module Simulation Actions vis-à-vis Guideline Recommendations
}

\author{
Michael D. Hagen, MD
}

The American Board of Family Medicine (ABFM) introduced Maintenance of Certification for Family Physicians in 2004 in response to policy adopted by the American Board of Medical Specialties. ${ }^{1}$ The ABFM reported in 2006 the initial Diplomate experiences with Maintenance of Certification for Family Physicians. ${ }^{2}$ At that time, the ABFM had Self-Assessment Modules (SAMs, consisting of a 60-item knowledge assessment followed by a virtual patient clinical simulation) available only for hypertension, type 2 diabetes mellitus, asthma, and depression. Since that time, the ABFM has deployed modules for coronary artery disease, chronic heart failure, well child care, maternity care, preventive care, care of the vulnerable elderly, pain management, early childhood illness, cerebrovascular disease, and health behavior. Each of the SAMs includes a Diplomate assessment of both the knowledge assessment and the simulation components.

In addition to the Diplomates' subjective assessments of the SAMs, the ABFM captures the actions taken during each simulation, including the action itself, the simulated date and time of the action, and the simulated patient's current health state. This information is captured in an action $\log$, which serves as a persistent record of the Diplomate's traversal through the simulation scenario.

Funding: none.

Conflict of interest: none declared.

Corresponding author: Michael D. Hagen, MD, American Board of Family Medicine, Inc., 1648 McGrathiana Parkway, 5th Floor, Lexington, KY 40511 (E-mail: mhagen@theabfm.org).
The ABFM introduced the congestive heart failure SAM and associated simulation in 2006. We present here a graphical summary of simulation actions taken in the congestive heart failure SAM as extracted from the simulation action logs from 2006 to 2011. We present the results as a percentage of simulations in which given actions occurred.

The results indicate overall high use of angiotensin-converting enzyme inhibitors and/or angiotensin receptor blockers but surprisingly low use of $\beta$-adrenergic blocking agents ( $\beta$-blockers). Digitalis preparations (DigitalisPrep) demonstrated very low use. The majority of Diplomates also did a formal assessment of left ventricular function (echocardiogram).

The CHF simulations generally present scenarios representing patients with stage $C$ heart failure, as defined in the 2009 American College of Cardiology Foundation/American Heart Association heart failure guideline. ${ }^{3}$ According to that guideline, ACE inhibitors and $\beta$-adrenergic blockers should routinely be used in these patients. ${ }^{3}$ This discrepancy between recommended therapy and the low percentage of $\beta$-adrenergic blocker prescriptions in the simulations suggests that the knowledge assessments should perhaps place greater emphasis on the use of these agents in class $\mathrm{C}$ heart failure. The current congestive heart failure knowledge assessment contains only 7 items that reference $\beta$-blockers, and nearly all these present a $\beta$-adrenergic agent only as historical information in the clinical stem of the item rather than as a focus of decision-making in the item.

These results suggest that the simulations, although clearly presenting a virtual patient environment, can serve as a useful probe for identifying possible management gaps that should 
Figure 1. Analysis of actions taken during the Chronic Heart Failure Simulations from 2005 through 2010. Percent is the percentage of simulations in which the action occurred. ACEInhibitors, an angiotensin converting enzyme (ACE) inhibitor prescribed; ACEInhibitorsARBS, ACE inhibitor or angiotensin receptor blocker prescribed; BetaBlockers, beta adrenergic blocking agent prescribed; DigitalisPrep, digitalis preparation prescribed; Echocardiogram, echocardiogram obtained; Hydralazine, hydralazine prescribed; Nitroglycerin, nitroglycerin prescribed; SmokingQuestions, patient queried regarding smoking behavior; StressImageStudy, Cardiac Stress Imaging Study obtained; TSH, thyroid stimulating hormone level obtained.

\section{CHF Actions}

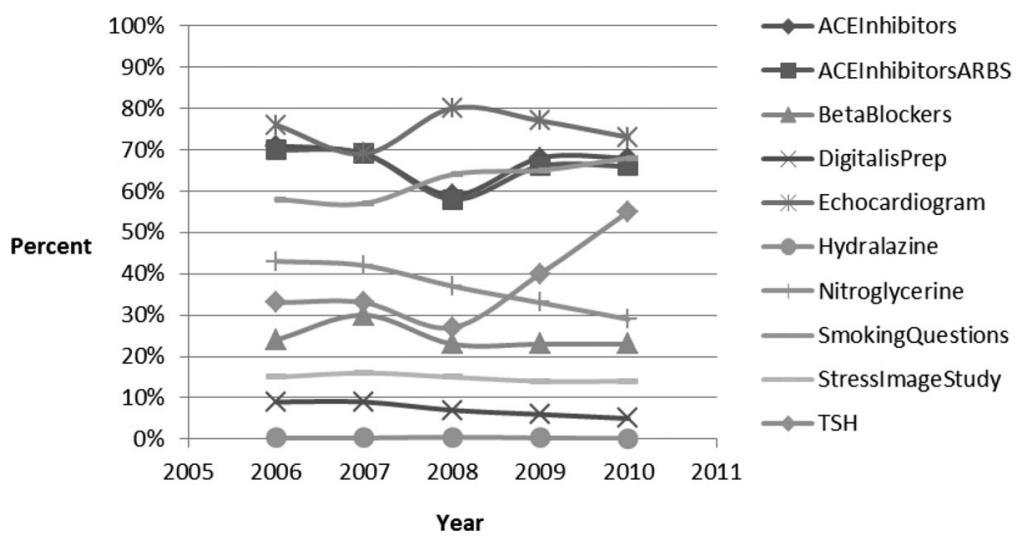

be emphasized in the SAM knowledge assessments. (Figure 1)

\section{References}

1. American Board of Medical Specialties. ABMS Maintenance of Certification. 2006 [cited July 29, 2011]. Available at: http://www.abms.org/ Maintenance_of_Certification/ABMS_MOC.aspx. Accessed April 28, 2012.
2. Hagen MD, Ivins D, Puffer JC, Rinaldo J, Roussel $\mathrm{GH}$, Sumner $\mathrm{W}, \mathrm{Xu}$ J. Maintenance of certification for family physicians (MC-FP) Self-Assessment Modules (SAMs): the first year. JABFM 2006;19: $398-403$.

3. Jessup M, Abraham WT, Casey DE, et al. 2009 focused update: ACCF/AHA guidelines for the diagnosis and management of heart failure in adults. Circulation 2009;119:1977-2016. 